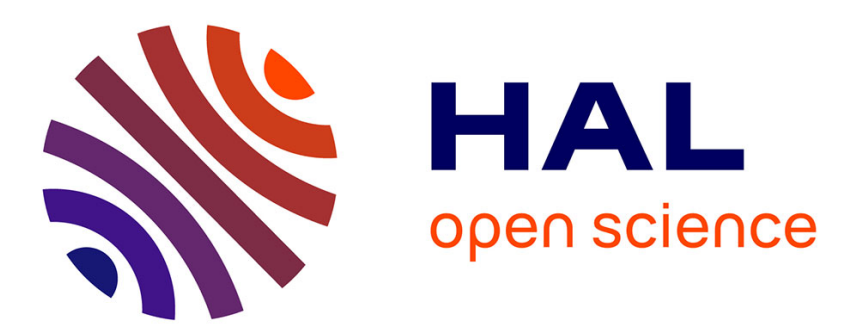

\title{
Catalysis by Metals: Contribution of Electrochemistry
}

\author{
J. Barbier, Marie-Josée J Chollier, Florence Epron
}

\section{To cite this version:}

J. Barbier, Marie-Josée J Chollier, Florence Epron. Catalysis by Metals: Contribution of Electrochemistry. Catalysis by Metals, Springer Berlin Heidelberg, pp.113-131, 1997, 10.1007/978-3-66206221-0_6. hal-03163038

\section{HAL Id: hal-03163038 \\ https://hal.science/hal-03163038}

Submitted on 9 Mar 2021

HAL is a multi-disciplinary open access archive for the deposit and dissemination of scientific research documents, whether they are published or not. The documents may come from teaching and research institutions in France or abroad, or from public or private research centers.
L'archive ouverte pluridisciplinaire HAL, est destinée au dépôt et à la diffusion de documents scientifiques de niveau recherche, publiés ou non, émanant des établissements d'enseignement et de recherche français ou étrangers, des laboratoires publics ou privés. 


\title{
Catalysis by Metals : Contribution of Electrochemistry
}

\author{
J. Barbier, M. J. Chollier and F. Epron
}

Laboratoire de Catalyse en Chimie Organique, URA 350 du CNRS, Universite de Poitiers, 40 avenue du Recteur Pineau, 86022 Poitiers, France

In Catalysis by metals, methods of electrochemistry can be mainly used in the two following areas :

- Preparation of bimetallic catalysts by surface redox reactions,

- Characterization of metallic catalysts.

\section{PREPARATION OF BIMETALLIC CATALYSTS BY SURFACE ELECTROCHEMICAL REACTIONS}

Preparation procedures of bimetallic catalysts influence the type of interaction between the two metallic species and then the catalytic performance of catalysts.

Different electrochemical methods can be used to bring into close contact the two metals responsible for the formation of the bimetallic entities. Four methods of preparing bimetallic catalysts were developed. These methods are direct redox reactions, redox reactions of adsorbed species, catalytic reduction and underpotential deposition [1].

\subsection{Direct redox reactions in the preparation of bimetallic catalysts}

In this case, metal-metal interactions result from surface redox reactions between the chemically prereduced metal «parent» $M$ and the oxidized form of the modifier $\mathrm{M}^{\prime} \mathrm{z}+$ +.

According to Nernst's law, the equilibrium potential of the reversible oxidation of $\mathrm{M}$ :

$$
\mathrm{M} \Leftrightarrow \mathrm{M}^{\mathrm{Z}+}+\mathrm{ze}
$$


$\mathrm{E}_{\mathrm{M}^{\mathrm{Z}} / \mathrm{M}}=\mathrm{E}_{\mathrm{M}^{\mathrm{Z}+} / \mathrm{M}}+\frac{\mathrm{RT}}{\mathrm{zF}} \operatorname{Ln} \frac{\mathrm{a}_{\mathrm{M}^{\mathrm{Z}}}}{\mathrm{a}_{\mathrm{M}}}$

where $\mathrm{a}_{\mathrm{M}^{\mathrm{z}}}$ and $\mathrm{a}_{\mathrm{M}}$ are the activities of oxidized $\left(\mathrm{M}^{\mathrm{Z}+}\right)$ and reduced $(\mathrm{M})$ species respectively and the other symbols have their usual meanings.

The equilibrium potential of the reversible reduction of $\mathrm{M}^{\mathrm{z}^{\prime+}}$

$$
\mathrm{M}^{\mathrm{z}^{\prime+}}+\mathrm{z}^{\prime} \mathrm{e} \Leftrightarrow \mathrm{M}^{\prime}
$$

is given by

$$
\mathrm{E}_{\mathrm{M}^{z^{\prime}+} / \mathrm{M}^{\prime}}=\mathrm{E}_{\mathrm{M}^{z^{\prime}+} / \mathrm{M}^{\prime}}^{\circ}+\frac{\mathrm{RT}}{z^{\prime} \mathrm{F}} \operatorname{Ln} \frac{\mathrm{a}_{\mathrm{M}^{z^{\prime}}}}{\mathrm{a}_{\mathrm{M}^{\prime}}} .
$$

If the value of the free energy difference $\Delta(\Delta G)$ is negative $\left(\Delta(\Delta \mathrm{G})=-\mathrm{zz} F\left(\mathrm{E}_{\mathrm{M}^{\prime} \mathrm{z}^{\prime}} / \mathrm{M}^{\prime}-\mathrm{E}_{\mathrm{M}^{\mathrm{z}} / \mathrm{M}}\right)\right)(3), \mathrm{M}^{\mathrm{z}^{\prime+}}$ will be reduced by the metal $\mathrm{M}$ as follows :

$$
\mathrm{z}^{\prime} \mathrm{M}+\mathrm{zM}^{\prime \mathrm{z}^{\prime}} \rightarrow \mathrm{zM}+\mathrm{z}^{\prime} \mathrm{M}^{\mathrm{z}^{+}}
$$

The system will tend to an equilibrium that corresponds to the equality of the two reversible potentials $\mathrm{E}_{\mathrm{M}^{\prime \mathrm{z}^{\prime}} / \mathrm{M}^{\prime}}$ and $\mathrm{E}_{\mathrm{M}^{\mathrm{z}} / \mathrm{M}}$ The rate of redox reactions depends on the topography of the metallic crystal.

An example of the use of direct redox reactions in the preparation of bimetallic catalysts is the deposition of ruthenium on Raney copper [2, 3] according to the reaction :

$$
3 \mathrm{Cu}(\mathrm{s})+2 \mathrm{Ru}^{3+} \rightarrow 3 \mathrm{Cu}^{2+}+2 \mathrm{Ru}(\mathrm{s}) .
$$

The modification of copper by redox reactions has been extended to other noble metals as $\mathrm{Ag}, \mathrm{Au}, \mathrm{Pd}, \mathrm{Pt}, \mathrm{Ir}$, and $\mathrm{Rh}[2]$ and to metals supported on oxides such as alumina and silica. 
1.2 Redox reactions of adsorbed species in the preparation of bimetallic catalysts (« Recharge method") [4-14]

This method is so called by Szabò and co-workers « adsorption of metallic ions via ionization of adsorbed hydrogen $»[4-7]$.

In this method, the ions of the modifier $\mathbf{M}^{\prime \mathbf{z}^{+}}$are reduced by a reagent (most commonly hydrogen) that preadsorbs selectively on the metal.

For instance, in the case of metals which adsorb hydrogen, as platinum, the adsorbed hydrogen can be considered as a source of electrons :

$$
\mathrm{H}_{\mathrm{ads}} \rightarrow \mathrm{H}^{+}+\mathrm{e} .
$$

Then the reduction of the modifier $\mathbf{M}^{\mathbf{z}^{\prime+}}$ can occur :

$$
\mathbf{M}^{\mathbf{z}^{\prime}}+\mathrm{z}^{\prime} \mathrm{H}_{\mathrm{ads}} \rightarrow \mathbf{M}_{\mathrm{ads}}^{\prime}+\mathrm{z}^{\prime} \mathrm{H}^{+}
$$

In this method, the prereduced monometallic catalyst is suspended in an electrolyte and treated with hydrogen until the surface of the catalyst is completely saturated by adsorbed hydrogen. Then, the reactor is flushed with inert gas to remove the hydrogen dissolved in the electrolyte. After outgassing, a deoxygenated solution containing the modifier $\mathrm{M}^{\prime \mathbf{z}^{\prime+}}$ is added.

An example of the use of the " recharge » method is the preparation of a monodispersed $\mathrm{Pt}_{\mathrm{Al}} \mathrm{O}_{3}$ by deposition of platinum onto a parent $\mathrm{Pt} / \mathrm{Al}_{2} \mathrm{O}_{3}$ [8], of platinum-gold, platinum-palladium, platinum-rhenium bimetallic catalysts [12-14].

\subsection{Catalytic reduction in the preparation of bimetallic catalysts}

From a thermodynamic stand point, molecular hydrogen in solution can reduce any metallic salt that has a redox potential greater than that of the $\mathrm{H}_{2} / \mathrm{H}^{+}$couple. However, at room temperature, the reduction of several metallic salts is kinetically limited.

The catalytic properties of the metal are used to increase the rate of reduction of the additive ion by means of a reducing agent, such as hydrogen, in solution. Thus the metal plays the role of the catalyst in the redox reaction :

$$
\begin{aligned}
& \text { catalyst } \\
& \mathrm{M}^{\mathrm{z}^{\prime+}}+\mathrm{H}_{2} \longrightarrow \mathrm{M}^{\prime}+\mathrm{zH}^{+} \text {. }
\end{aligned}
$$

In such conditions, the additive is deposited on the catalytic site that is active for the reduction reaction. If the parent catalyst consists of a metal supported on a conductor, the additive will deposit competitively on the parent metal and on the support. 
To date, the catalytic reduction of copper on platinum, on rhodium, on ruthenium and of rhenium on platinum has been investigated [14-16].

\section{4 Underpotential deposition $[17,18]$}

Underpotential deposition consists in the formation of a metal monolayer at potentials more positive than the reversible Nernst potential, that is before bulk deposition can occur.

In the bulk deposition of a metal M', according to the reaction :

$$
\mathbf{M}^{\mathbf{z}^{\prime}+}+\mathrm{z}^{\prime} \mathrm{e} \Leftrightarrow \mathbf{M}^{\prime}
$$

the activity of the deposited metal is assumed to be constant and equal to one. In this case, the equilibrium potential is :

$$
\mathrm{E}_{\mathrm{M}^{\prime \mathrm{z}^{\prime}+} / \mathrm{M}^{\prime}}=\mathrm{E}_{\mathrm{M}^{\prime \mathrm{z}^{\prime}+} / \mathrm{M}^{\prime}}+\frac{\mathrm{RT}}{\mathrm{z}^{\prime} \mathrm{F}} \operatorname{Ln} \mathrm{a}_{\mathrm{M}^{\mathrm{z}^{\prime}+}}
$$

When $\mathrm{M}^{\prime}$ is deposited in submonolayer $\left(\mathrm{M}_{\mathrm{ML}}^{\prime}\right)$ on the metal $\mathrm{M}$, the coverage $\theta$ of $\mathrm{M}$ by $\mathrm{M}^{\prime}$ and then the activity of $\mathrm{M}^{\prime}$ in submonolayer $\mathrm{a}_{\mathrm{M}^{\prime}}{ }_{\mathrm{ML}}$ are less than one

$$
\mathrm{a}_{\mathrm{M}^{\prime}}{ }_{\mathrm{ML}}=\gamma_{\mathrm{M}^{\prime}} \theta
$$

where $\gamma_{\mathrm{M}}$ is the activity coefficient of $\mathrm{M}^{\prime}$.

For the deposition of a submonolayer of metal, the equilibrium potential can be given by

$$
E_{M^{\prime z^{\prime}+} / M^{\prime}}(\theta)=E_{M^{\prime z^{\prime}+} / M^{\prime}}^{\circ}+\frac{R T}{z^{\prime} F} \operatorname{Ln} \frac{C_{M^{z^{\prime}}+\gamma_{M^{z^{\prime}+}}}}{\theta \gamma_{M^{\prime}}}
$$

The equilibrium potential $\mathrm{E}(\theta)$ of the submonolayer is always more positive than the Nernst potential of bulk deposition. As a result, an underpotential deposition (UPD) of adatoms of M' on M can occur.

Underpotential deposition leads to formation of submonolayers before three dimensional bulk deposition occurs and the coverage varies with the poiential and time of deposition. UPD is characterized by the existence of adatoms.

The formation of submonolayers of different adatoms by UPD differs substantially depending on the substrate structure and the crystal orientation. This finding shows up the large interest of this technique. Indeed with heterogeneous polycrystalline surface, the deposition potential can be controlled such that adatoms adsorb preferentially on specific sites of the polycrystal. 
The simplest methods for investigating UPD are electrochemical.

Examples of the use of UPD technique are the modification of platinum catalyst by copper [10, 19], arsenic [20], gold [21], iron [22], lead and tin [23,24] and the modification of palladium $[25,26]$.

\subsection{Concluding remarks}

Surface redox reactions represent a relatively new approach to prepare supported bimetallic catalysts. Three main techniques have already been identified :

- direct redox reactions between the parent metal and the modifier,

- redox reactions between a reductant and the modifier (the reductant can be previously adsorbed on the parent metal or introduced as a reagent in the reactor (if no homogeneous reaction can occur between the modifier and the reductant)),

- underpotential deposition.

All these variants are complementary to one another and by using different experimental conditions, different ligands, different reductants and different modes of preparation, this approach can apparently be used to prepare any type of bimetallic couple. But the catalytic properties of the final catalyst will depend strongly on the technique used. The selection of one variant over another depends on the desired structure of the bimetallic phase.

In conclusion, redox reactions allow the surface to be tailored during catalyst preparation, which explains the exceptional properties, particularly in terms of selectivity, of bimetallic catalysts prepared by these techniques.

\section{CHARACTERIZATION OF METALLIC CATALYSTS BY THE MEANS OF ELECTROCHEMICAL METHODS}

Transient electrochemical methods allow, through the measurement of the quantity of electricity obtained in response to a potential variation, to detect the surface modifications of the electrode due to the electrochemical formation or destruction of superficial layers.

One of the most widely used transient electrochemical methods is cyclic voltammetry with linear potential sweep. It consists in applying to the working electrode a potential $E$ that varies in a linear way with time and recording the corresponding $i=f(E)$ curves.

A voltammogram is characteristic of the nature of the metal and of the adsorbed species in given experimental conditions.

So this method presents the advantage of characterizing the catalyst « in situ " and allows [10, 27-30] :

- the determination of the initial area of the catalyst,

- the determination of the quantity of adsorbed compound on the surface of the catalyst,

- the determination of the adsorption stoechiometry,

- the determination of the adsorption isotherms and thermodynamic parameters. 


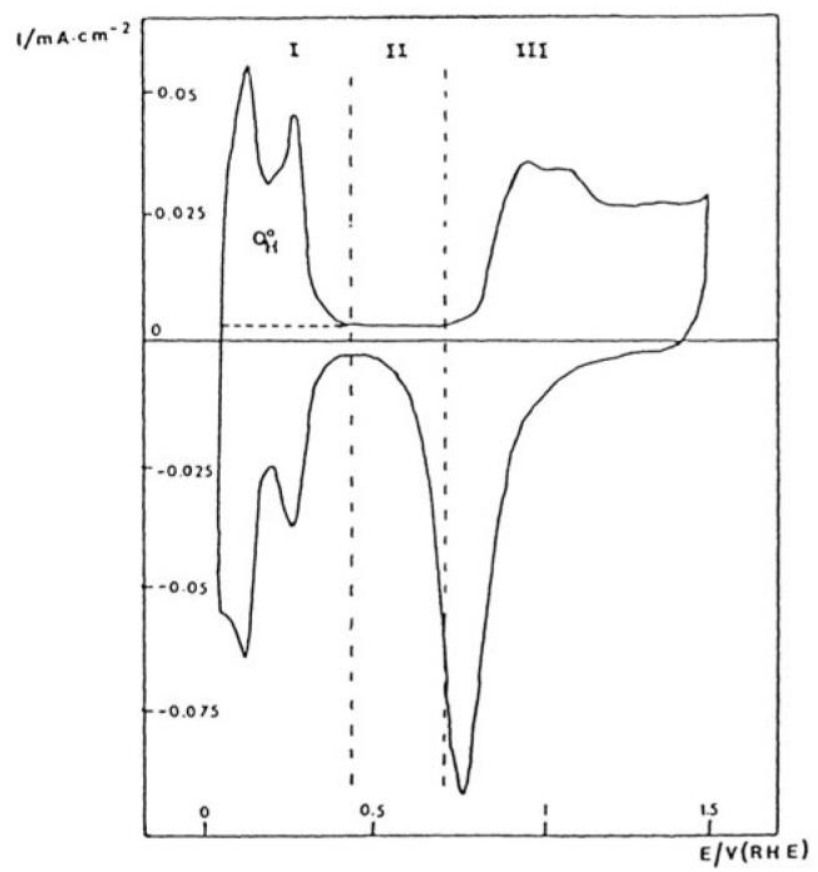

Figure 1 : Cyclic voltammogram of a platinized platinum catalyst electrode in $0.5 \mathrm{M} \mathrm{H}_{2} \mathrm{SO}_{4}$. Sweep rate $50 \mathrm{mV} . \mathrm{s}^{-1} \cdot[31]$

The voltammogram of platinum can be divided into three regions (Fig. 1) :

- region I corresponding to the adsorption ( $\mathrm{i}<0: \mathrm{H}^{+}+\mathrm{e}^{-} \rightarrow \mathrm{H}_{\text {ads }}$ ) and the desorption ( $\mathrm{i}>0 \quad: \mathrm{H}_{\mathrm{ads}} \rightarrow \mathrm{H}^{+}+\mathrm{e}^{-}$) of hydrogen (from 0.05 to $0.5 \mathrm{~V} / \mathrm{RHE})$. The perfect symmetry of the anodic and cathodic curves confirms the reversibility of the equilibrium $\mathrm{H}^{+}+\mathrm{e}^{-} \Leftrightarrow \mathrm{H}_{\mathrm{ads}}+$ on platinum.

- region II in which no electrochemical reaction occurs (from 0.5 to $0.65 \mathrm{~V} / \mathrm{RHE}$ ).

- region III corresponding to the adsorption (i $>0$ :

$\left.\mathrm{H}_{2} \mathrm{O} \rightarrow \mathrm{O}_{\mathrm{ads}}+2 \mathrm{H}^{+}+2 \mathrm{e}^{-}\right)$and desorption ( $\mathrm{i}<0: \mathrm{O}_{\mathrm{ads}}+2 \mathrm{H}^{+}+2 \mathrm{e}^{-} \rightarrow \mathrm{H}_{2} \mathrm{O}$ ) of oxygen (from 0.65 to $1.5 \mathrm{~V} / \mathrm{RHE}$ ). The lack of reversibility of the adsorption and desorption peaks indicates that the kinetics of these two opposites are slow. 


\subsection{Determination of metallic surface area by cyclic voltammetry}

Through integration of the anodic or cathodic part relative to the hydrogen potential region of the voltammogram [28], it is possible to obtain the quantity of electricity, $\mathrm{Q}_{\mathrm{H}}^{\mathrm{O}}$, associated with an hydrogen monolayer and to calculate the initial number, $\mathrm{N}_{\mathrm{o}}$, of the surface platinum atoms (see Fig. 1) :

$$
\mathrm{N}_{\mathrm{o}}=\frac{\mathrm{Q}_{\mathrm{H}}^{\mathrm{O}}(\mu \mathrm{C})}{1.6 .10^{13}}
$$

or the initial surface area (assuming that a platinum atom occupies an average area close to $7.6 \AA^{2}$, i.e $1.31 .10^{15}$ atoms per $\mathrm{cm}^{2}$ ).

2.2 Thermodynamic study of the adsorption of different compounds by cyclic voltammetry

The free energy of adsorption $\Delta G$ can be determined by means of transient electrochemical methods. As a matter of fact, the electrooxidation or the electroreduction of the adsorbed species is a function of the free energy of adsorption given by Gibbs equation :

$$
\Delta \mathrm{G}=-\mathrm{zFE}
$$

The partial derivative of free energy in relation to the temperature, in a reduced range of temperature, can be written :

$$
\frac{\partial \Delta \mathrm{G}}{\partial \mathrm{T}}=-\mathrm{zF} \frac{\partial \mathrm{E}}{\partial \mathrm{T}}=-\Delta \mathrm{S}
$$

The ratio $\frac{\partial \mathrm{E}}{\partial \mathrm{T}}$ can be determined by making the measurement of two values of the potential of the catalyst, at two different temperatures.

Consequently the energy of adsorption $\Delta \mathrm{H}$ can be deduced from $\Delta \mathrm{G}$ and $\Delta \mathrm{S}$ measurements.

\subsubsection{Thermodynamic study of hydrogen adsorption on platinum}

Reactions of electroreduction of protons or electrooxydation of hydrogen are fast on platinum. As a consequence the equilibrium corresponding to the overall reaction : 


$$
\mathrm{H}_{2} \Leftrightarrow 2 \mathrm{H}^{+}+2 \mathrm{e}^{-}
$$

is assured at every moment.

Thus, any catalyst working in liquid phase and in the presence of hydrogen behaves like a reversible hydrogen electrode whose potential obeys Nernst equation

$$
\mathrm{E}=0.06 \log \left[\mathrm{H}^{+}\right]-0,03 \log \mathrm{pH}_{2}
$$

Hence, the measurement of the potential is a measurement of the hydrogen pressure near the catalyst and therefore of hydrogen coverage. The cyclic voltammetry curves (see Fig. 1) allow, for any potential value, to define the amount of hydrogen adsorbed at that same potential (by integration of the amount of electricity associated with the reaction $\mathrm{H}^{+}+\mathrm{e}^{-} \rightarrow \mathrm{H}_{\mathrm{ads}}$ ).

The potential at which the electrochemical reaction occurs can be correlated to the free energy corresponding to this reaction and given by the Gibbs equation :

$$
\Delta \mathrm{G}=-\mathrm{zFE}=\Delta \mathrm{H}-\mathrm{T} \Delta \mathrm{S}
$$

The voltammogram (see Fig. 1) shows two peaks of hydrogen adsorption or desorption corresponding to two different potentials, hence to different energies of adsorption. The first peak, relative to a strongly bound hydrogen, appears at a potential $\mathrm{E}=0.26 \mathrm{~V} / \mathrm{RHE}$ (low hydrogen coverage). The second peak which corresponds to a weakly bound hydrogen appears at $0.13 \mathrm{~V} / \mathrm{RHE}$ (high hydrogen coverage).

The above potentials are measured in relation to a reference electrode, so it is not possible to define the true energy of adsorption corresponding to the different forms of adsorbed hydrogen.

However, the potential difference between the two peaks $(0.13 \mathrm{~V})$ shows that there is, between each form of hydrogen, a difference of energy of adsorption. equal to :

$$
\begin{aligned}
\Delta(\Delta \mathrm{G}) & =\mathrm{zF} \Delta \mathrm{E} \\
& =2 \times 96500 \times 0.13 \\
& \cong 25 \mathrm{~kJ} / \mathrm{mol} .
\end{aligned}
$$

On the other hand the temperature coefficient $\frac{\partial \mathrm{E}}{\partial \mathrm{T}}$ allows to calculate the entropy variation related to the hydrogen adsorption reaction. Table I gives the temperature coefficients and the entropy variations relative to hydrogen both strongly and weakly bound. 
Table I : Temperature coefficients and entropy variations relative to hydrogen adsorption on platinum[32].

\begin{tabular}{|c|c|c|}
\hline Hydrogen & $\frac{\partial \mathrm{E}}{\partial \mathrm{T}}\left(\mathrm{V} \cdot \mathrm{K}^{-1}\right)$ & $\Delta \mathrm{S}\left(\mathrm{J} \cdot \mathrm{K}^{-1} \mathrm{~mol}{ }^{-1}\right)$ \\
\hline weakly bound & $2.74 \cdot 10^{-3}$ & -530 \\
strongly bound & $3.21 \cdot 10^{-3}$ & -620 \\
\hline
\end{tabular}

It must be remarked that the entropy variations are negative, which correspond to a loss of degrees of freedom when the hydrogen molecule in gas phase passes into the state of adsorbed hydrogen atoms. Moreover the weakly bound hydrogen has lost a smaller degree of freedom during its adsorption and so it is more mobile on the surface of the catalyst. Moreover

$$
\Delta(\Delta \mathrm{H})=\Delta(\Delta \mathrm{G})+\mathrm{T} \Delta(\Delta \mathrm{S}) \cong 50 \mathrm{~kJ} / \mathrm{mol}
$$

This value is comparable to the one given in the literature $[33,34]$.

The cyclic voltammetry curves (see Fig. 1) allow, for any potential value, to define the amount of hydrogen adsorbed. On the other hand, according to Nernst equation for a given $\mathrm{pH}$, (equation 10 ), the potential is directly linked to the hydrogen pressure.

Consequently, it is possible to plot the hydrogen adsorption isotherms (see Fig. 2).

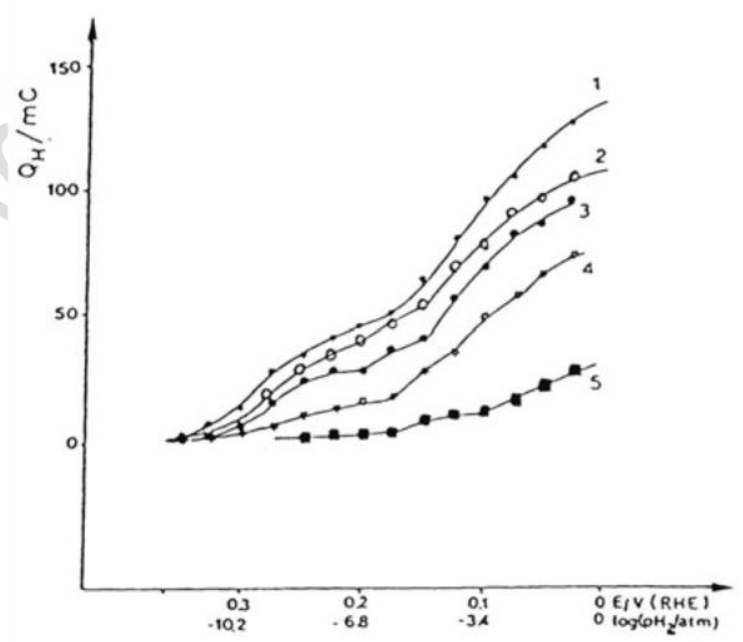

Figure 2: Adsorption isotherms of hydrogen on platinum modified by sulphur at different sulphur coverages [29] (1) 0 ; (2) 0.04 , (3) 0.07 , (4) 0.17 , (5) 0.73 . 
The isotherm (see Fig.2) is formed by two waves which are in relation with the two forms of hydrogen previously described. Each of these waves follows a Temkin type law which allows the determination of the free energy of hydrogen adsorption on the catalyst.

\subsubsection{Thermodynamic study of sulphur adsorption on platinum}

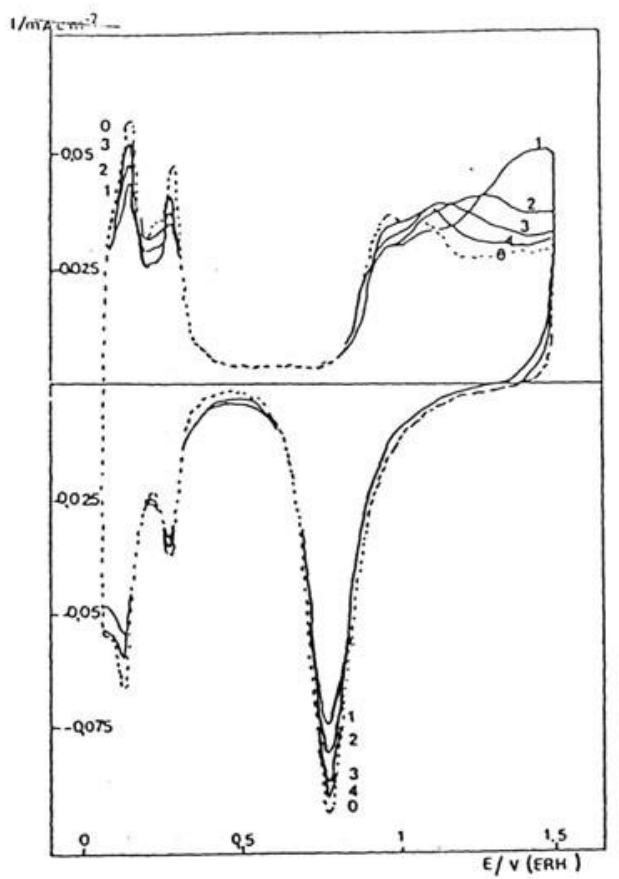

Figure 3 : Cyclic voltammogram curves of platinized platinum electrode modified by sulphur during successive cycles $\left(\mathrm{H}_{2} \mathrm{SO}_{4} 0.5 \mathrm{M} ; 50 \mathrm{mV} / \mathrm{s} ; 25^{\circ} \mathrm{C} ; \theta \mathrm{s}=0.27\right)$ [30], - in absence of adsorbed sulphur, in presence of adsorbed sulphur.

Sulphur adsorbed on a platinized platinum electrode modifies the cyclic voltammetry curves characteristic of this metal.

In the adsorption region of hydrogen, a decrease of the high of the adsorption or desorption peaks shows that a fraction of the surface has been occupied by sulphur, thus inhibiting the adsorption of hydrogen, (Fig. 3). 
Moreover, the sulphur coverage can be introduced by the relation :

$$
\theta_{\mathrm{S}}=\frac{\mathrm{Q}_{\mathrm{H}}^{\mathrm{O}}-\mathrm{Q}_{\mathrm{H}}^{\mathrm{S}}}{\mathrm{Q}_{\mathrm{H}}^{\mathrm{O}}}
$$

where $\mathrm{Q}_{\mathrm{H}}^{0}$ and $\mathrm{Q}_{\mathrm{H}}^{\mathrm{S}}$ are the quantities of electricity associated with the oxidation of adsorbed hydrogen in the absence and in the presence of sulphur.

The quantity of adsorbed sulphur can be determined by its electrooxidation which leads to its desorption to the state of sulphate [35-36]. This electrochemical study allows to determine the oxidation state and the stoichiometry of adsorbed sulphur on platinium $[30,31]$.

The effect of preadsorbed sulphur on the adsorption of hydrogen on platinum allows to obtain the evolution of the free energy of adsorption of hydrogen on platinum (for both strongly and weakly bound hydrogen) as a function of sulphur coverage, defined by the isotherms of hydrogen adsorption (Tab.II).

Table II : Effect of sulphur on the free energy of adsorption of hydrogen on platinum [29]

\begin{tabular}{|c|c|c|}
\hline $\mathrm{N}_{\mathrm{S}} / \mathrm{N}_{\mathrm{Pt}}$ & $\begin{array}{c}\text { Strongly bound } \\
\text { hydrogen } \\
-\Delta \mathrm{G}^{\circ} \\
(\mathrm{kJ} / \mathrm{mol})\end{array}$ & $\begin{array}{c}\text { Weakly bound } \\
\text { hydrogen } \\
-\Delta \mathrm{G}^{\circ} \\
(\mathrm{kJJ} / \mathrm{mol})\end{array}$ \\
\hline 0 & 37 & 14 \\
0.04 & 36 & 13 \\
0.07 & 31 & 12 \\
0.17 & 30 & 7 \\
0.72 & 38 & 0.5 \\
\hline
\end{tabular}

Sulphur doesn't modify the free energy of adsorption of strongly bound hydrogen. But on the other hand, it affects strongly the adsorption equilibrium constants of weakly bound hydrogen. 


\subsubsection{Thermodynamic study of maleic acid adsorption}

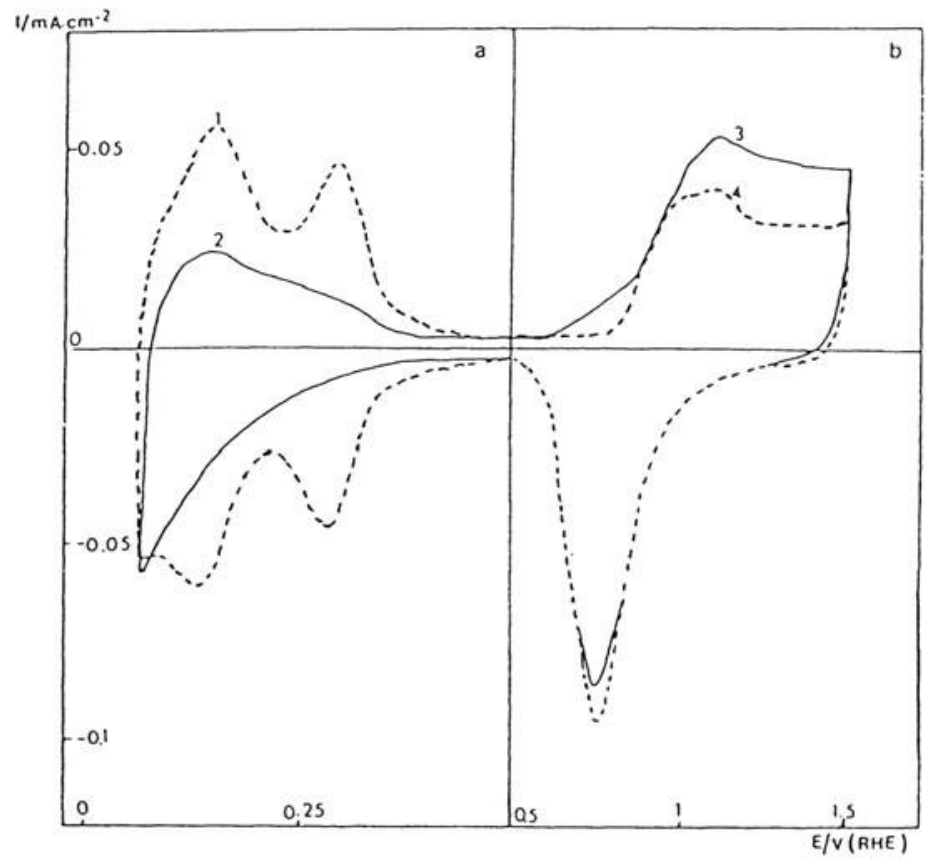

Figure 4 : Effect of the adsorption of maleic acid on the cyclic voltammogram of platinized platinum catalyst electrode $\left(0.5 \mathrm{M} \mathrm{H}_{2} \mathrm{SO}_{4} ; 50 \mathrm{mV} / \mathrm{sec}\right)$ [31] (-)in absence of adsorbed maleic acid, (_ $)$ in presence of adsorbed maleic acid; (a) cyclic voltammogram in the region of adsorption- desorption of hydrogen;(b) cyclic voltammogram in the region of adsorption- desorption of oxygen.

Figure 4a shows a voltammogram recorded in the region of hydrogen after adsorption of maleic acid. The decrease of the hydrogen peaks proves that hydrogen and unsaturated compounds adsorb in competition on the same sites.

A comparison of the two curves, 3 and 4, of Figure 4, recorded between 0.5 and $1.5 \mathrm{~V} / \mathrm{RHE}$, in the presence and the absence of adsorbed maleic acid, shows that the oxidation of this adsorbed compound causes an increase of the anodic current.

Through integration of the difference between curves 1 and 2, the degree of coverage, $\theta_{\mathrm{M}}$, of the catalyst by maleic acid can be determined as the fraction of the surface deactivated for hydrogen chemisorption.

$$
\theta_{\mathrm{M}}=\frac{\left(\mathrm{Q}_{\mathrm{H}}^{\mathrm{O}}-\mathrm{Q}_{\mathrm{H}}^{\mathrm{M}}\right)}{\mathrm{Q}_{\mathrm{H}}^{\mathrm{O}}}
$$


where $\mathrm{Q}_{\mathrm{H}}^{\mathrm{O}}$ and $\mathrm{Q}_{\mathrm{H}}^{\mathrm{M}}$ are the quantities of electricity associated with the oxidation of adsorbed hydrogen in the absence and in the presence of maleic acid.

Furthermore, adsorption isotherms of maleic acid can be determined by measurement of $\theta_{M}$ for different acid concentrations (Fig. 5).

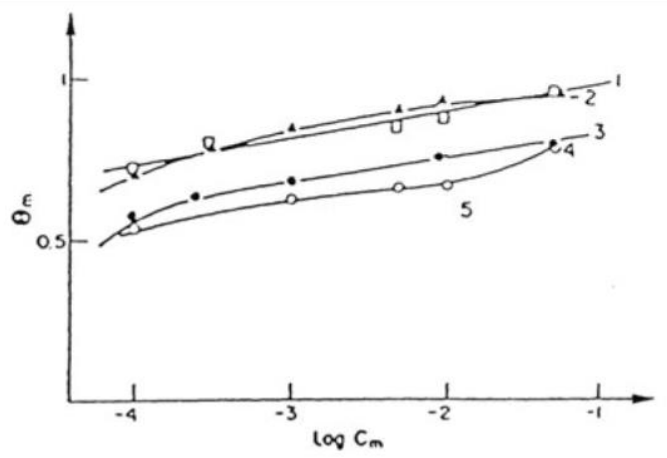

Figure 5 : Adsorptions of maleic acid $\left(C=10^{-2} \mathrm{M}\right)$ on Pt/Pt electrodes of different roughness parameters : (1) 2.3, , (2) 22, , (3) 58, , (4) 300, (5) 360 [38].

The quantity of maleic acid adsorbed on a platinum electrode can be determined by integration of the difference between curves 3 and 4 of Figure 4 , which leads to the quantity of electricity $\mathrm{Q}_{\mathrm{Ox}}^{\mathrm{M}}$ associated to the oxidation of this adsorbate, according to reaction :

$\mathrm{HOOC} \quad \mathrm{COOH}$

$$
\mathrm{C}=\mathrm{C} \quad+4 \mathrm{H}_{2} \mathrm{O} \quad \rightarrow \quad 4 \mathrm{CO}_{2}+12 \mathrm{H}^{+}+12 \mathrm{e}^{-}
$$

$\mathrm{H} \quad \mathrm{H}$

If $\mathrm{nPt}_{\mathrm{M}}$ is the number of platinum sites occupied by one molecule of adsorbed maleic acid, it can be written :

$$
\frac{Q_{H}^{O}-Q_{H}^{M}}{n_{P t_{M}}}=\frac{Q_{\mathrm{ox}}^{\mathrm{M}}}{12}
$$


It has been found $[10,31]$ that one molecule of adsorbed maleic acid occupies about 5 accessible platinum atoms.

2.3 Electrochemical potential of the catalyst during hydrogenation reactions in liquid phase

Figure 6 and 7 [37] show the evolution of the potential of platinum catalyst and of maleic acid concentration versus working time during an hydrogenation reaction of maleic acid. It can be noted a sudden increase of the potential during the maleic acid introduction. This variation corresponds to a diminution of hydrogen coverage on the catalyst. The more the reaction progresses the more the potential tends to its initial value. A metallic catalyst working in liquid phase and in the presence of hydrogen behaves like a reversible hydrogen electrode.

The change of the catalytic activity of platinum, for the hydrogenation of maleic acid, as a function of the electrochemical potential, is shown in Figure 8. It can be seen that the catalyst is inactive for potentials higher than 0.2 V/R.H.E.

The comparison of the results of hydrogenation of maleic acid at controlled potentials with the voltammetry data related to the adsorption of hydrogen shows that at potentials below 0.2 V/R.H.E. only weakly adsorbed hydrogen is consumed, whereas at potentials above 0.2 V/R.H.E. about half of the platinum surface is covered by very inactive strongly bound hydrogen species.

It can be concluded therefore that during the liquid- phase hydrogenation reactions of $\mathrm{C}=\mathrm{C}$ bonds, only weakly bound hydrogen species are active. Moreover this hydrogen is also most mobile on the platinum surface.

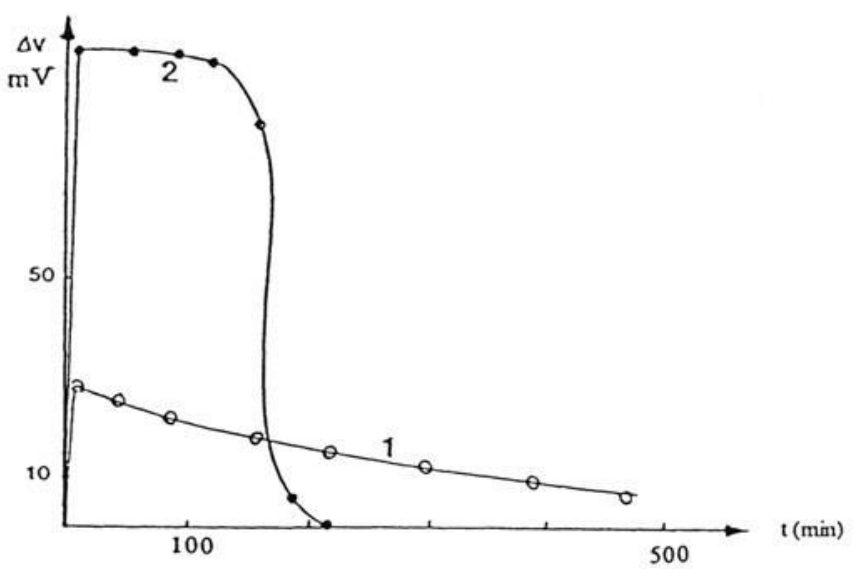

Figure 6: Evolution of the potential of a Pt catalyst versus working time during hydrogenation reaction [37] (Curve 1:25 mg of Pt, curve 2 : $100 \mathrm{mg}$ of Pt). 


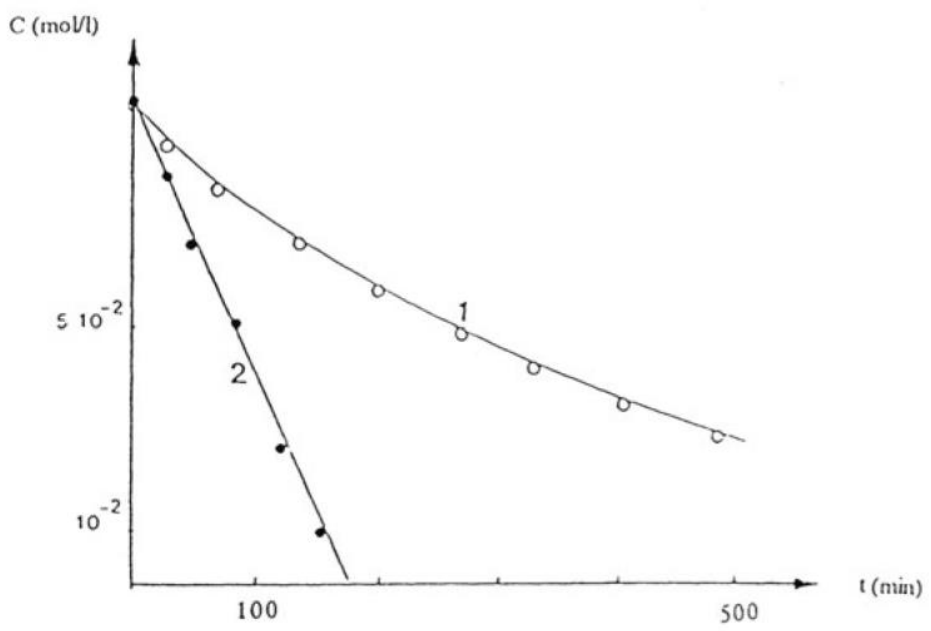

Figure 7 : Evolution of maleic acid concentration versus working time during hydrogenation reaction [37] (Curve 1:25 mg of Pt, curve 2: $100 \mathrm{mg}$ of $\mathrm{Pt}$ ).

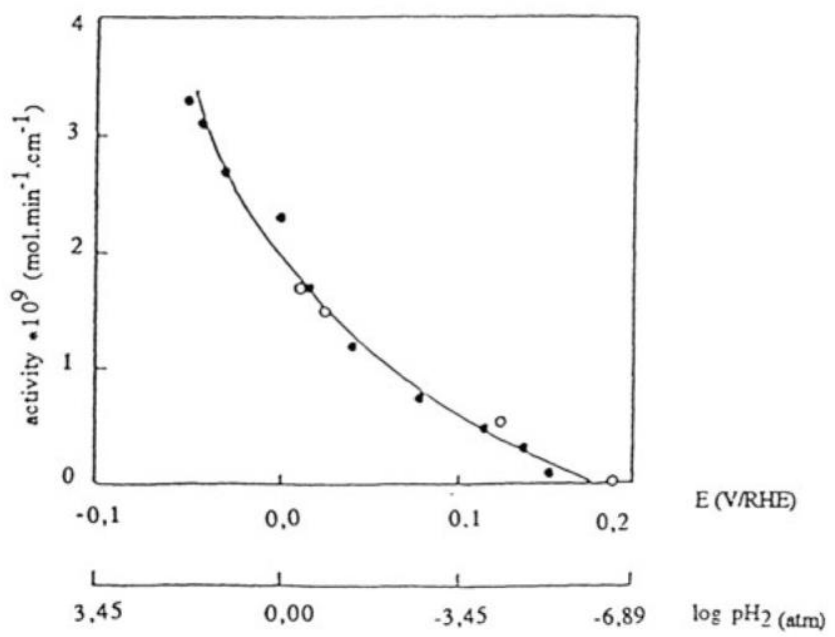

Figure 8 : Catalytic activity of platinum for the hydrogenation of maleic acid as a function of the potential of the catalyst [38] 
Furthermore, the starting reduction potential is lower (more weakly adsorbed hydrogen) for more substituted olefins (Table 3)

Table III : Comparison of activities of platinum catalysts at different potentials, in catalytic hydrogenation of maleic (MA), methylmaleic (MMA) and dimethylmaleic (DMMA) acids ( $\left.\mathrm{C}=10^{-3} \mathrm{M}\right)[39]$.

\begin{tabular}{|cc|c|c|}
\hline \multirow{2}{*}{$\begin{array}{c}\text { Potential } \\
(\mathrm{mV} / \mathrm{RHE})\end{array}$} & \multicolumn{3}{c|}{ Activity $10^{9}\left(\mathrm{~mol} / \mathrm{min} . \mathrm{cm}^{2}\right)$} \\
\cline { 2 - 4 } & MA & MMA & DMMA \\
254 & 0 & 0 & 0 \\
204 & 0 & 0 & 0 \\
184 & 0.06 & 0 & 0 \\
154 & 0.09 & 0.07 & 0 \\
124 & 0.21 & 0.16 & 0.06 \\
103 & 0.23 & 0.19 & 0.16 \\
93 & 0.29 & 0.22 & 0.19 \\
\hline
\end{tabular}

Thanks to which it is possible to control the selectivity, in competitive hydrogenation of maleic and methylmaleic acid by imposition of different potentials (Tab. IV) [39].

Table IV : Variation of the selectivity $\mathrm{S}_{\mathrm{MA}} / \mathrm{S}_{\mathrm{MMA}}$ in competitive hydrogenation of maleic and methylmaleic acids as a function of the potential of the catalyst.

\begin{tabular}{|c|c|}
\hline $\begin{array}{c}\text { Potential } \\
(\mathrm{mV} / \mathrm{RHE})\end{array}$ & $\begin{array}{c}\text { Selectivity } \\
\mathrm{S}_{\mathrm{MA}} / \mathrm{S}_{\mathrm{MMA}}\end{array}$ \\
\hline 9 & 1.7 \\
69 & 3.1 \\
150 & 7.0 \\
171 & 50 \\
\hline
\end{tabular}

On the other hand, Table $\mathrm{V}$ shows the change of the selectivity as a function of the potential of the catalyst in the hydrogenation of acetylenic compounds such as butynedioic acid on platinum. It is worth noting that weakly bound hydrogen which is active in olefinic compounds hydrogenation leads to a low selectivity in alkene during the hydrogenation of acetylenic compounds [32]. 
Table $\mathbf{V}$ : Variation of the selectivity in olefinic compounds during hydrogenation of butynedioic acid as a function of the potential of the catalyst [32].

\begin{tabular}{|c|c|}
\hline Potential & $\begin{array}{r}\text { Selectivity in olefinic } \\
\text { compounds } \\
\mathrm{C}=\mathrm{C} / \mathrm{C}-\mathrm{C} \%\end{array}$ \\
\hline 9 & 6 \\
4 & 7 \\
86 & 26 \\
\hline
\end{tabular}

Moreover, the strongly bound hydrogen, is more active for the hydrogenation of acetylenic bonds, than for the hydrogenation of the double bound. This allows to explain the increase in the selectivity in alkene as soon as the coverage in weakly bound hydrogen decreases.

\subsection{Concluding remarks}

The characterization of the surface state and of the chemisorbed species on metallic catalysts working in liquid phase can be carried out "in situ " by a transient electrochemical method : the linear potential sweep cyclic voltammetry. The use of that technique allows :

- the determination at the initial metallic area of the catalyst,

- the measurement of the surface area occupied by reagents or by modifiers,

- the evaluation of the adsorption stoechiometry,

- the measurement of the equilibrium coverage of the adsorbed species which allows to obtain the adsorption isotherms and thermodynamics of that adsorption.

On the other hand, during catalytic hydrogenation of unsaturated compounds, the activity and selectivity of platinum catalysts depends on the value of working potential of the catalyst.

Using such electrochemical studies of catalytic hydrogenation reactions pointed out that only weakly adsorbed hydrogen species are involved in hydrogenation of olefinic compounds on platinum catalysts.

\section{Acknowledgements}

The authors are gratefull to all the persons of the laboratory of whom the work allows us to write this course :

Montassier.

Permanent Researchers : E. Lamy-Pitara, P. Marecot, J.C. Menezo, C.

Students : L. Bencharif, L. El Ouazzani-Benhima, M.E. Gonzalez,

L. Lghouzouani, S. Moukolo, J. Naja, S. Peyrovi, C.L. Pieck, Y. Tainon. 


\section{References}

[1] J. Barbier, Redox Reactions in the Tailoring of Bimetallic Catalysts.

Advances in Catalysts Preparation, Catalytica Studies Division (1992) 3.

[2] C. Montassier, J.C. Ménézo, S. Moukolo, J. Naja, J. Barbier. Heterogeneous Catalysis and Fine Chemicals II, Stud. Sci. Catal., M. Guisnet, J. Barrault. C. Bouchoule, D. Duprez, G. Perot, R. Maurel, C. Montassier Eds. 59. (1991) 223.

[3] J. Barbier, J.P. Boitiaux, P. Chaumette, S. Leporq, J.C. Ménézo. C. Montassier, EP 380, 402, assigned to Institut Français du Petrole (1990).

[4] S. Szabó, F. Nagy, J. Electroanal. Chem., 84, (1977) 93.

[5] S. Szabó, F. Nagy, J. Electroanal. Chem., 85, (1977) 339.

[6] S. Szabó, F. Nagy, J. Electroanal. Chem., 吕, (1978) 261.

[7] S. Szabó, F. Nagy, J. Electroanal. Chem., 160, (1984) 299.

[8] J.C. Ménézo, M.F. Denanot, S. Peyrovi, J. Barbier. Appl. Catal.. 15, (1985) 353.

[9] S. Szabó, F. Nagy, React. Kinet. Catal. Lett., 351 (2), (1987)133.

[10] E. Lamy-Pitara, J. Barbier, C. Lamy, J. Chim. Phys., 77 (10) (1980) 967.

[11] J. Margitfalvi, S. Szabó, F. Nagy, Stud. Surf. Sci. Cat., 17 (1986) 373.

[12] S. Szabó, F. Nagy, Isr. J. Chem., 18, (1979) 162.

[13] J. Margitfalvi, S. Szabó, F. Nagy, S. Gobolos, M. Hegedus, Preparation of catalysts III, Stud. Surf. Sci. Catal., G. Poncelet, P. Grange, P.A. Jacobs, Eds, Elsevier, Amsterdam, 16, (1983).

[14] C.L. Pieck, P. Marecot, J. Barbier, Appl. Cat. A, 134, (1996) 319

[15] C.L. Pieck, P. Marecot, C.A. Querini, J.M. Parera, and J. Barbier, Appl. Cat. A, 133, (1995) 281.

[16] C.L. Pieck, Ph. D. Thesis, University of Poitiers (1994).

[17] D.M. Kolb, Adv. Electrochem. Electrochem. Engineer., 11 (1978)125.

[18] S. Szabó, International Reviews in Physical Chemistry, 10 (2). (1991) 207.

[19] S.H. Calde, S. Buckenstein, Anal. Chem., 43, (1971) 1858 .

[20] N. Furuya, S. Motoo, J. Electroanal. Chem., 72, (1976) 165.

[21] N. Furuya, S. Motoo, J. Electroanal. Chem., $\underline{78}$, (1977) 243.

[22] N, Furuya, S. Motoo, J. Electroanal. Chem., $\underline{\mathbf{8 8}},(1978) 151$.

[23] E. Lamy-Pitara, L. El Quazzani-Benhima, and J. Barbier, J. Electroanal. Chem., 335, (1992) 363.

[24] N. Furuya, S. Motoo, J. Electroanal. Chem., 98, (1979) 195.

[25] I. Bakos, S. Szabo, F. Nagy. T. Mallat, Z. Bodnar, J. Electroanal. Chem., 309, (1991) 203

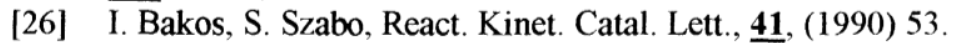
(1976) 89.

[27] E. Lamy-Pitara and J. Barbier, Electrochimica Acta, 27 (6) (1982) 713.

[28] R. Woods, Chemisorption at electrodes : hydrogen and oxygen on noble metals and their alloys, Electroanal. Chem., Vol.9, ed. A.J. Bard, Marcel Dekker Inc, N.Y. (1976)

[29] E. Lamy-Pitara, L. Lghouzouani, Y. Tainon, J. Barbier, J. Electroanal. Chem, 260, 157 (1989) 
[30] E. Lamy- Pitara, L. Bencarif, J. Barbier, Electrochem. Acta, 30, 971 (1985)

[31] E. Lamy- Pitara, L. Bencharif, J. Barbier, Appl. Cat., 18, 117 (1985)

[32] J. Barbier, E. Lamy- Pitara, P. Marecot, Bull. Soc. Chim. Bel., 105, 99 (1996).

[33] K.R. Cristmann in " Hydrogen Effects in Catalysis». ed. Z. Paal and P.G. Menon, M. Dekker, N.Y. 3 (1988).

[34] K. Cristmann and G. Ertl Surf. Sci. 60, (1976) 365.

[35] A.A. Sutyagina, B.A. Perepelitsa and M.N. Semenko, Rh. Fiz. Khim., 57 (3) , (1985). 681

[36] A.A. Sutyagina, B.A. Perepelitsa and M.N. Semenko, Rh. Fiz. Khim., 57 (3) (1985) 685

[37] J. Barbier, M. E Gonzalez, J. Chim. phys, $7 \underline{6}$ (1979)

[38] E. lamy-Pitara, I. Belegridi, L. El Ouazzani-Benhima, J. Barbier, Catalysis Letters, 19, (1993) 87.

[39] E. Lamy-Pitara, I. Belegridi, J. Barbier, Catalysis Today, 24, (1995) 151. 